\title{
BIOESTIMULANTE VIA FOLIAR EM ALFACE APÓS O TRANSPLANTIO DAS MUDAS
}

\section{TARCEL HENRIQUE CORREIA IZIDÓRIO ${ }^{1}$, SEBASTIÃO FERREIRA DE LIMA ${ }^{1}$, EDUARDO PRADI VENDRUSCOLO ${ }^{2}$, JORGIANI DE ÁVILA ${ }^{1}$, RITA DE CÁSSIA FÉLIX ALVAREZ ${ }^{1}$}

\footnotetext{
1 Universidade Federal de Mato Grosso do Sul, Chapadão do Sul/MS, Brasil, tarcel.henrique@hotmail.com, sebastiao.lima@ufms.br, jorgianiavila@hotmail.com, rita.alvarez@ufms.br; ${ }^{2}$ Universidade Federal de Goiás/UFG - Escola de Agronomia, Goiânia/GO, Brasil, agrovendruscolo@gmail.com.
}

RESUMO: A alface é considerada a hortaliça folhosa de maior importância nacional. O aumento da demanda e exigência sobre a qualidade do produto estimula a utilização de novas tecnologias, como os bioestimulantes, na etapa produtiva. O objetivo, neste trabalho, foi o de avaliar o efeito da aplicação foliar do bioestimulante comercial Stimulate ${ }^{\circledR}$ durante o transplantio nas características agronômicas da cultura da alface, cultivar Amanda. $\mathrm{O}$ delineamento experimental foi em blocos casualizados com seis tratamentos, compostos por seis doses de bioestimulante $\left(0,0 ; 3,0 ; 6,0 ; 9,0 ; 12,0 ; 15,0 \mathrm{~mL} \mathrm{~L}^{-1}\right)$, aplicadas sobre as mudas de alface transplantadas para a área experimental em quatros repetições. O experimento foi instalado em julho de 2013, na horta experimental da Universidade Federal de Mato Grosso do Sul, Campus de Chapadão do Sul/MS utilizando-se a cultivar Amanda. Foram avaliados: o número de folhas por planta (NF), matéria seca de folhas (MSF), massa seca total (MST), diâmetro da cabeça (DC) e a matéria fresca da cabeça (MFC). A aplicação da solução contendo 7,0 $\mathrm{mL} \mathrm{L}^{-1}$ de bioestimulante, em mudas de alface após o transplantio, resultou em maior número de folhas por planta. No entanto, a utilização do produto foi prejudicial para as características de diâmetro de cabeça, fitomassa fresca de folha, fitomassa seca de folha e fitomassa seca total.

PALAVRAS-CHAVE: Lactuca sativa, fitormônios, Stimulate ${ }^{\circledR}$, reguladores de crescimento.

\section{BIOSTIMULANT FOLIAR APPLICATION IN LETTUCE AFTER TRANSPLANTING OF SEEDLINGS}

\begin{abstract}
Lettuce (Lactuca sativa L.) is the leaf vegetable most planted in Brazil. The increase in demand and requirement on product quality favors the use of new technologies such as the use of biostimulants. The objective of this study was to evaluate the effect of foliar application of biostimulant Stimulate ${ }^{\circledR}$ during transplanting on the agronomic characteristics of lettuce cultivar Amanda. The experimental design was a randomized block with six treatments, consisting of six doses of biostimulant $\left(0.0,3.0,6.0,9.0,12.0,15.0 \mathrm{~mL} \mathrm{~L}^{-1}\right)$, applied on the lettuce seedlings transplanted to the experimental area in four repetitions. The experiment was installed in July 2013 using cultivar Amanda. The number of leaves per plant (NL), leaf dry matter (LDM), total dry matter (TDM), head diameter (HD) and head fresh matter (HFM) were evaluated. The foliar application of the solution containing $7.0 \mathrm{~mL} \mathrm{~L}^{-1}$ of biostimulant in lettuce seedlings after the transplanting resulted in a higher number of leaves per plant. However, the use of the product was detrimental to the head diameter, leaf fresh matter, dry matter and the total leaf dry matter.
\end{abstract}

KEYWORDS: Lactuca sativa, biostimulant, Stimulate ${ }^{\circledR}$, plant growth regulators. 


\section{INTRODUÇÃO}

No Brasil, a alface é considerada a hortaliça folhosa de maior importância na alimentação da população, o que torna esta cultura de grande expressão econômica (LOPES et al., 2007), principalmente para pequenos produtores, principais fornecedores para o mercado.

Com a expansão de redes fast-food em todo o país, segundo Sala e Costa (2008) houve um consequente aumento na demanda da hortaliça e consequentemente em sua cultura. Os mesmos autores também apontam um maior consumo desta cultura na época do verão, quando saladas folhosas são preferidas.

A melhoria e a difusão das técnicas de manejo na produção de culturas hortícolas resultam em aumento da competitividade no mercado, onde se buscam produtos que se sobressaiam diante da boa qualidade daqueles já existentes. Técnicas alternativas de produção e produtos promotores do crescimento e desenvolvimento vegetal são algumas das soluções para a obtenção de olerícolas de alta qualidade.

Os bioestimulantes são misturas de um ou mais reguladores de crescimento com outros compostos de natureza química diferente, como sais minerais (CASTRO; PEREIRA, 2008). Estes compostos são utilizados com sucesso em espécies de interesse agronômico como, arroz, milho, feijão, cebola e alface (ALBRECHT et al., 2009; BERNARDES SOARES et al., 2012; LESZCZYNSKI et al., 2012).

Repke et al. (2009) conduziram experimento com aplicação de Stimulate ${ }^{\circledR}$ em alface americana e crespa (variedades "Lucy Brown" e "Verônica") e observaram efeitos benéficos no crescimento das plantas; elevação do teor de clorofila total na alface americana, aumento do diâmetro médio das plantas e fitomassa das plantas de alface crespa. Na dose de $150 \mathrm{~mL}$ $\mathrm{ha}^{-1}$ de Stimulate ${ }^{\circledR}$ estes autores observaram um aumento relevante no crescimento vegetativo com maior fitomassa médio das plantas (variedade "Verônica") e para a variedade "Lucy Brown", a dose de $100 \mathrm{~mL} \mathrm{ha}^{-1}$ resultou em maiores teores de clorofila total.

Em estágios iniciais de desenvolvimento de plântulas, a aplicação de reguladores de crescimento pode promover maior crescimento do sistema radicular do vegetal possibilitando a rápida recuperação da planta após, o estresse hídrico, além de propiciar a planta maior tolerância a insetos, pragas, doenças e nematoides. Os reguladores de crescimento ainda promovem o estabelecimento de plantas de forma rápida e uniforme o que pode proporcionar maior obtenção de nutrientes e o rendimento da planta (DANTAS et al., 2012).

Frente ao exposto, evidencia-se a importância de estudos mais aprofundados sobre a utilização dos bioestimulantes em culturas de interesse comercial. Sendo assim, objetivou-se avaliar o efeito da aplicação do bioestimulante comercial Stimulate ${ }^{\circledR}$ via foliar em época de transplantio, sobre as características agronômicas da cultura da alface, cultivar Amanda.

\section{MATERIAL E MÉTODOS}

O experimento foi conduzido na horta experimental da Universidade Federal de Mato Grosso do Sul, Campus de Chapadão do Sul - MS, localizada nas coordenadas $18^{\circ} 46^{\prime} 17,8^{\prime \prime}$ de latitude sul, $52^{\circ} 37^{\prime} 27,7^{\prime \prime}$ de longitude oeste e com altitude de $813 \mathrm{~m}$. O solo da área foi classificado como Latossolo Vermelho Distrófico argiloso (EMBRAPA, 2013). Os dados climatológicos foram obtidos do INMET, a partir da estação automática localizada em Chapadão do Sul, MS (Figura 1).

O delineamento experimental estabelecido foi em blocos casualizados com seis tratamentos e quatros repetições, resultando em 24 parcelas no total. Os tratamentos foram 
compostos por seis doses de solução contendo diferentes proporções de bioestimulante comercial Stimulate $^{\circledR}\left(0,0 ; 3,0 ; 6,0 ; 9,0 ; 12,0 ; 15,0 \mathrm{~mL} \mathrm{~L}^{-1}\right)$, diluído em água e aplicado via foliar no momento do transplantio de cada muda de alface transplantada para a área experimental. $\mathrm{O}$ volume total da solução aplicada foi de $50 \mathrm{~mL}$ por muda. A parcela foi constituída de quatro linhas de $1,8 \mathrm{~m}$ de comprimento, com seis plantas por linha. $\mathrm{O}$ espaçamento utilizado foi o de $0,30 \times 0,30 \mathrm{~m}$, entre linhas e plantas. A parcela útil foi constituída pelas duas linhas centrais, com 12 plantas e área de $1,08 \mathrm{~m}^{2}$.

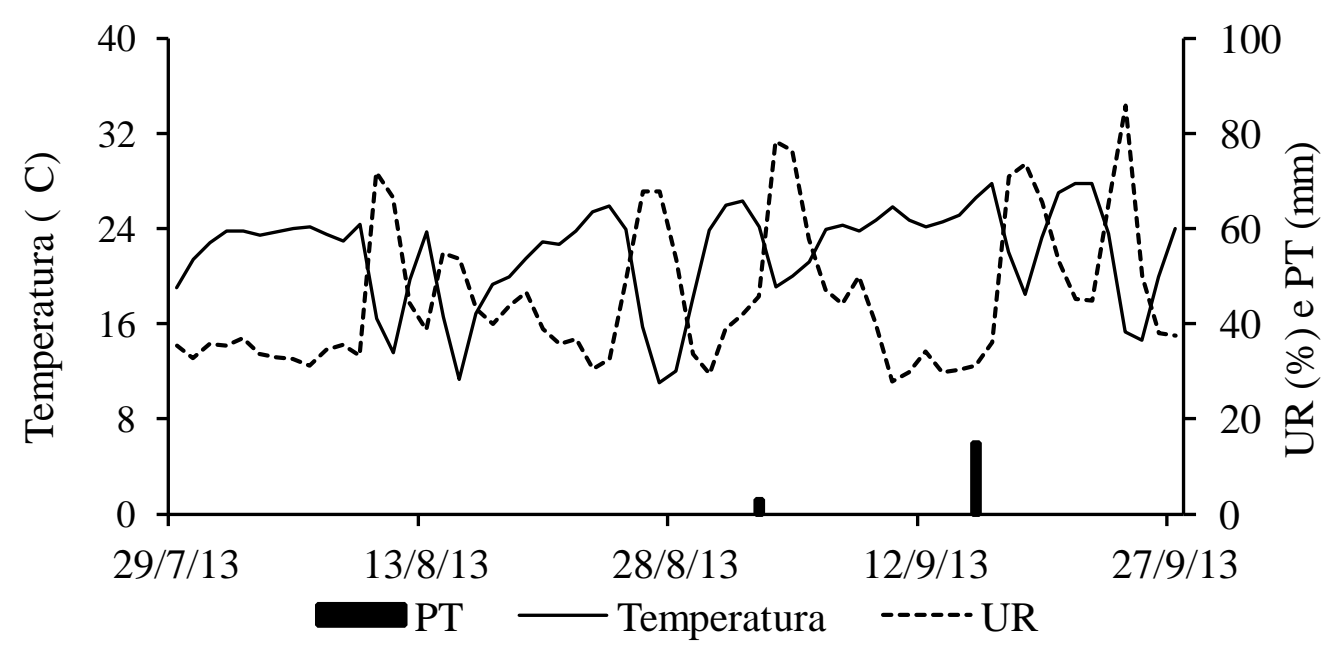

Figura 1. Médias da precipitação total (PT), temperatura e umidade relativa (UR), ocorridas durante o período de condução do experimento em Chapadão do Sul, MS

O bioestimulante utilizado possui em sua composição 0,009\% de cinetina (citocinina), 0,005\% de ácido giberélico (giberilina), 0,005\% de ácido indolbutírico (auxina) (STOLER DO BRASIL, 1998).

O experimento foi instalado em 29 de julho do ano de 2013 utilizando a alface Amanda. A adubação de plantio foi realizada manualmente, em sulcos, e incorporada ao solo com a utilização de enxadas. A quantidade de adubo foi calculada de acordo com recomendação para a cultura da alface conforme Filgueira (2008), mediante análise de solo. As fontes de adubo utilizadas foram a ureia $(45 \%$ de $\mathrm{N})$, o superfosfato simples $(18 \%$ de $\mathrm{P}_{2} \mathrm{O}_{5}$ ) e o cloreto de potássio $\left(58 \%\right.$ de $\mathrm{K}_{2} \mathrm{O}$ ) nas doses de $30 \mathrm{~kg} \mathrm{~N} \mathrm{ha}^{-1}, 400 \mathrm{~kg} \mathrm{P}_{2} \mathrm{O}_{5} \mathrm{ha}^{-1}$ e 90 $\mathrm{kg} \mathrm{K}_{2} \mathrm{O} \mathrm{ha}^{-1}$. A adubação de cobertura foi feita com $30 \mathrm{~kg} \mathrm{~N} \mathrm{ha}^{-1}$, aplicada em três vezes a cada 15 dias, iniciando 15 dias após o transplante das mudas. $\mathrm{O}$ adubo foi distribuído no entorno das plantas utilizando-se recipientes plásticos.

A composição do solo presente na área experimental foi verificada por análise laboratorial, na qual foram obtidas as seguintes características: $8,0 \mathrm{mg} \mathrm{dm}^{-3} \mathrm{de} \mathrm{P}$ (Mehlich); $31,1 \mathrm{~g} \mathrm{dm}^{-3}$ de M.O.; 4,8 de pH (CaCl2); $\mathrm{K}^{+}, \mathrm{Ca}^{2+}, \mathrm{Mg}^{+2}$ e $\mathrm{H}+\mathrm{Al}=0,38 ; 2,80 ; 1,10$ e 4,9 $\mathrm{cmol}_{\mathrm{c}} \mathrm{dm}^{-3}$, respectivamente, e $46,6 \%$ de saturação por bases

As mudas utilizadas no experimento foram semeadas em bandejas de polietileno com 128 células, contendo o substrato comercial Plantmax ${ }^{\circledR}$. Foram mantidas em casa de vegetação protegida por cobertura plástica, sombreada com telado $50 \%$ de luminosidade (sombrite) e com irrigação por aspersão automatizada, acionada duas vezes ao dia, sendo posteriormente transplantadas para o local definitivo quando as mudas apresentaram 3 a 5 folhas definitivas. 
Durante a condução do experimento foi realizado apenas o controle de plantas daninhas por meio de capinas manuais conforme a necessidade. Não houve incidência de pragas e doenças. Também não foram realizadas reposição de mudas, uma vez que não ocorreu perda das mesmas nos canteiros.

O manejo de irrigação foi feito por meio de mangueiras perfuradas do tipo Santeno, com dois furos, com espaçamento de 3 metros entre cada linha de irrigação. A necessidade de água foi calculada considerando o $\mathrm{KC}$ da cultura igual a 1.

A colheita ocorreu aos 49 dias após o transplantio. Nesse momento foram realizadas as avaliações na cultura, sendo que em duas plantas por parcela foram avaliadas o número de folhas por planta (NF), a fitomassa seca de folhas em gramas (MSF) e a fitomassa seca total em gramas (MST) e em outras quatro plantas por parcela foram determinados o diâmetro da cabeça em centímetros (DC) e a fitomassa fresca da cabeça em gramas (MFC).

A análise de regressão foi utilizada para verificar o ajuste de modelos polinomiais para variáveis dependentes, em função das doses de solução com as diferentes concentrações de Stimulate $^{\circledR}$ aplicadas nas mudas transplantadas, em nível de $5 \%$ de probabilidade.

\section{RESULTADOS E DISCUSSÃO}

Todas as características avaliadas, número de folhas por planta (NF), diâmetro da cabeça (DC), fitomassa fresca de folhas (MF), fitomassa seca de folha (MSF) e fitomassa seca total (MST) foram influenciadas pelas doses de bioestimulante, permitindo o ajuste dos dados a regressão quadrático para NF (Figura 2) e linear negativa para DC, MF, MSF e MST (Figura 3).

$\mathrm{O}$ aumento da concentração de bioestimulante propiciou o aumento do número de folhas de alface, até a dose de $7,0 \mathrm{~mL} \mathrm{~L}^{-1}$ de bioestimulante; ponto de máximo na equação de regressão (Figura 2), quando ocorreu um acréscimo de 3 folhas, representando um aumento de $8,2 \%$ em relação a testemunha. Entretanto, concentrações maiores de bioestimulante afetaram negativamente o número de folhas. Na concentração máxima, ocorreu redução de $3 \%$ na produção de folhas de alface, em comparação com a testemunha.

$\mathrm{O}$ aumento do número de folhas pode estar relacionado ao contato direto de gemas axilares com o produto aplicado, sendo que a citocinina presente na solução pode antagonizar o efeito inibitório promovido pela auxina, produzida pelo meristema apical da planta de alface, sobre o desenvolvimento das gemas (TAIZ; ZEIGER, 2009). O efeito de quebra da dormência de gemas laterais também foi observado em estudo com imersão de ramos de batata-doce em solução contendo bioestimulante, onde o aumento da concentração de Stimulate ${ }^{\circledR}$ até a dose de $9,8 \mathrm{~mL} \mathrm{~L}^{-1}$ proporcionou aumento do número de folhas (RÓS et al., 2015).

O número de folhas constitui uma variável importante para a comercialização da alface, sendo esta uma hortaliça folhosa cuja parte aérea é comercializada (FILGUEIRA, 2008). Entretanto, esta variável pode não refletir o desempenho da mesma, considerando que a planta pode apresentar muitas folhas, mas de tamanho reduzido, o que refletirá no tamanho da "cabeça" que é a variável mais importante visualmente no momento da comercialização do produto.

O uso de bioestimulante reduziu o diâmetro de "cabeça" da alface (Figura 3). Na maior concentração do produto, foi verificada uma redução de $5,8 \mathrm{~cm}$, representando $16,3 \%$, quando comparado a testemunha. Esta característica é uma das mais importantes e observadas pelo consumidor no momento de aquisição da alface, que é comercializada fresca e por 
unidade. Esses resultados foram diferentes dos observados por Repke et al. (2009), que ao conduzirem experimento com aplicação de Stimulate $^{\circledR}$ em alface americana e crespa, obtiveram aumento do diâmetro médio das plantas em que o produto foi aplicado $(0,75 ; 1,00$; 1,$25 ; 1,50 ; 1,75 \mathrm{~mL} \mathrm{~L}^{-1}$ ), em relação ao tratamento controle sem aplicação.

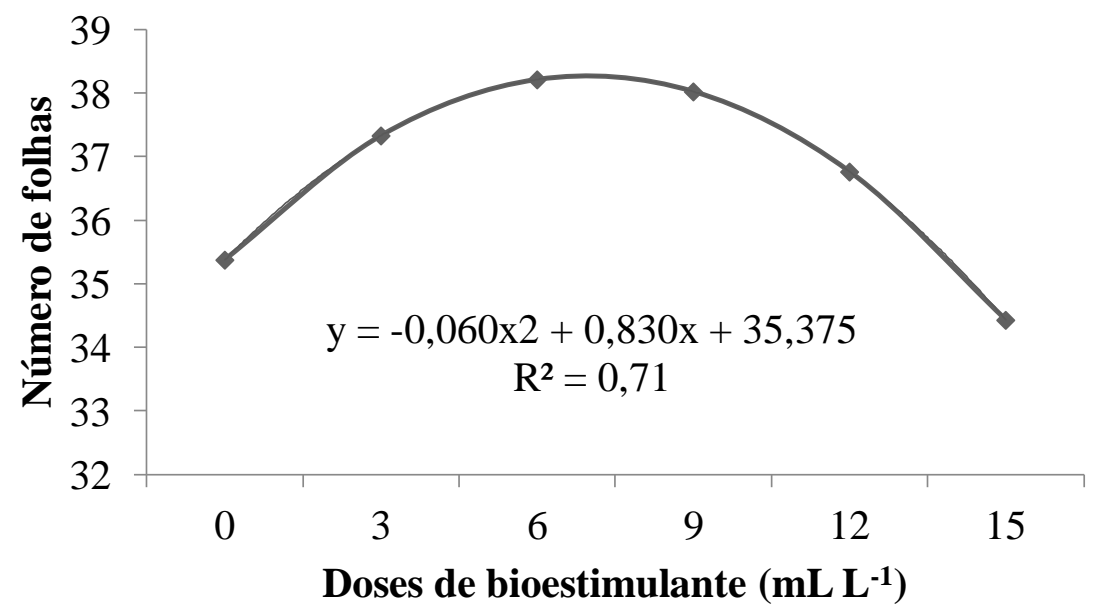

Figura 2. Número de folhas da alface cultivar Amanda, aos 49 dias após o transplantio, em resposta à aplicação de bioestimulante nas mudas após o transplantio. Campus de Chapadão do Sul - MS.

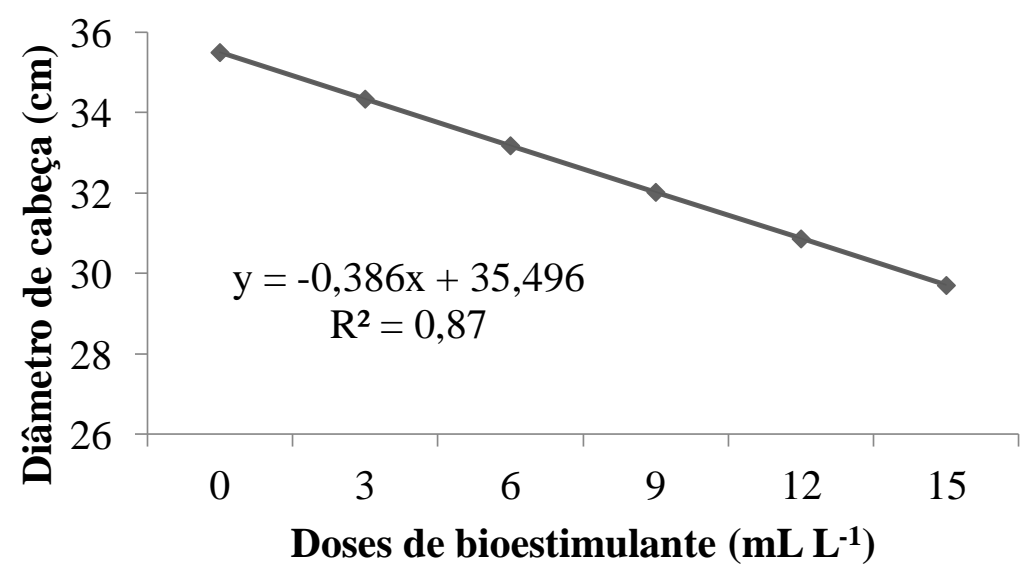

Figura 3. Diâmetro de cabeça $(\mathrm{cm})$ de alface Amanda aos 49 dias após o transplantio em resposta à aplicação de bioestimulante nas mudas após o transplantio. Campus de Chapadão do Sul - MS.

Os efeitos negativos da aplicação das diferentes concentrações do bioestimulante podem ser reflexos da atuação dos fitormônios como ácido indolbutírico e cinetina, presentes no bioestimulante comercial, causando alteração no balanço hormonal das plantas, pois segundo Taiz e Zeiger (2009), quando há ocorrência da aplicação acima dos níveis ótimos de auxinas e citocininas, mesmo estes fitormônios fazendo parte da complexa atividade de divisão celular, pode ocorrer efeito marcante na inibição do crescimento dos órgãos vegetais.

Assim, concordando com o disposto por Campos et al. (2008) que obtiveram resultados negativos quanto à aplicação de bioestimulante Stimulate ${ }^{\circledR}$ nas doses de 1,7 e 3,4 $\mathrm{mL} \mathrm{L}^{-1}$ sobre as características de área foliar e fitomassa seca da parte aérea. Em contrapartida os mesmos autores evidenciam o favorecimento do crescimento radicular pela aplicação do produto nestas mesmas doses, sugerindo uma possível interação positiva entre os reguladores vegetais presentes no produto. 
A aplicação de bioestimulante reduziu a fitomassa fresca de folhas da alface (Figura 4). Sendo que na concentração máxima utilizada do produto, ocorreu redução de $100,1 \mathrm{~g}$ planta $^{-1}$, correspondendo a $26,9 \%$ da fitomassa, em comparação a testemunha.

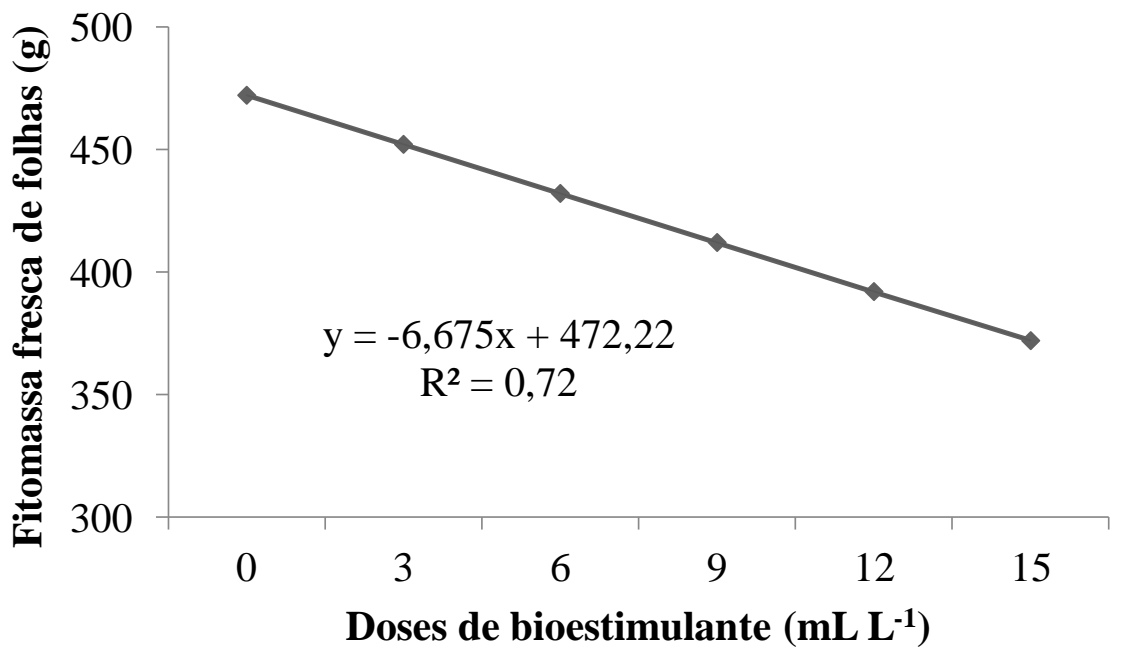

Figura 4. Fitomassa fresca de folhas $\left(\mathrm{g} \mathrm{planta}^{-1}\right)$ de alface cultivar Amanda aos 49 dias após o transplantio, em resposta à aplicação de bioestimulante nas mudas após 0 transplantio. Campus de Chapadão do Sul - MS.

Verificou-se para fitomassa seca de folhas, redução em seu valor com o aumento das concentrações de bioestimulante aplicados nas mudas de alface (Figura 5). Na maior concentração do produto foi verificada uma redução de $7,0 \mathrm{~g} \mathrm{planta}^{-1}$ na fitomassa seca de folhas, representando $51,1 \%$ de perda em relação à testemunha.

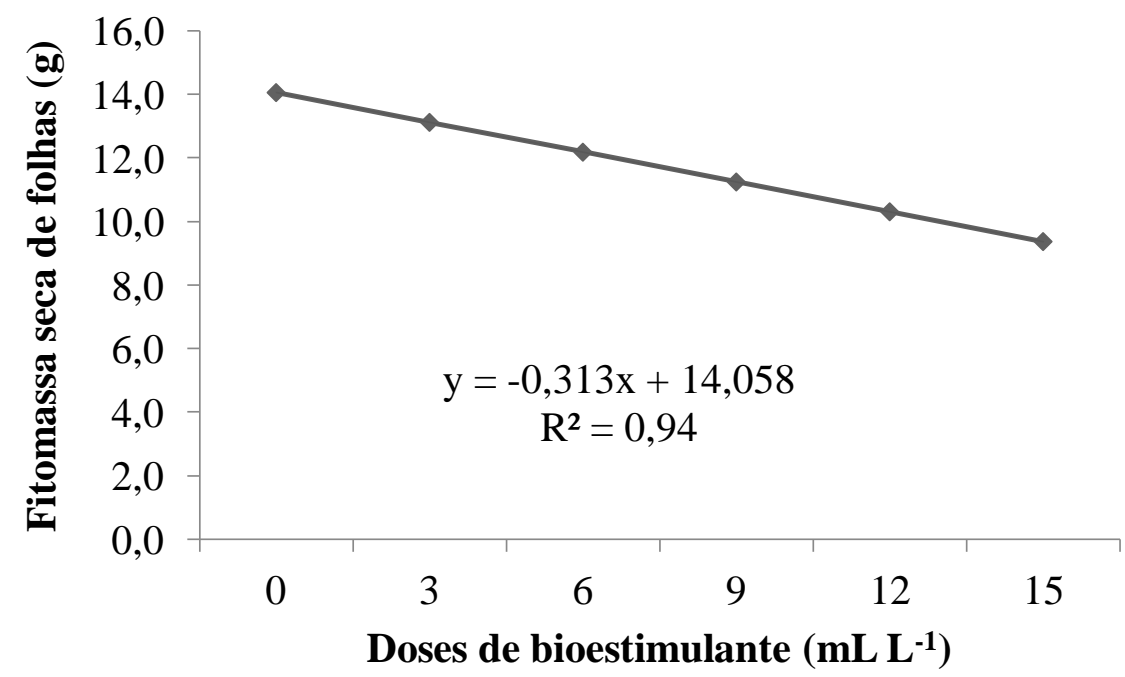

Figura 5. Fitomassa seca de folhas $\left(\mathrm{g} \mathrm{planta}^{-1}\right)$ de alface Amanda aos 49 dias após o transplantio, em resposta à aplicação de bioestimulante nas mudas após o transplantio. Campus de Chapadão do Sul - MS.

Trabalhando com a cultura do fumo, Vieira e Almeida (2010) verificaram que a aplicação de Stimulate ${ }^{\circledR}\left(0,0 ; 1,0 ; 3,0 ; 5,0 ; 11,0 \mathrm{~mL} \mathrm{~L}^{-1}\right)$, em condições de viveiro, reduziu a fitomassa seca de folha e área foliar, fitomassa seca da haste e fitomassa seca da raiz. Todavia, Repke et al. (2009) conduziram experimento com aplicação de Stimulate $^{\circledR}(0,0$; 
0,$75 ; 1,00 ; 1,25 ; 1,50 ; 1,75 \mathrm{~mL} \mathrm{~L}^{-1}$ ) em alface americana e crespa (variedades "Lucy Brown" e "Verônica") e observaram efeitos benéficos do produto no desenvolvimento das plantas, elevação do teor de clorofila na alface americana, aumento do diâmetro médio das plantas e fitomassa das plantas de alface crespa.

Seguindo a tendência da variável fitomassa seca de folhas, por ser uma hortaliça folhosa, a fitomassa seca total também foi reduzida com o aumento das doses de bioestimulante (Figura 6). Na maior dose do produto ocorreu redução de $4,8 \mathrm{~g} \mathrm{planta}^{-1}$ na massa seca total, correspondendo a $45,5 \%$ de perda.

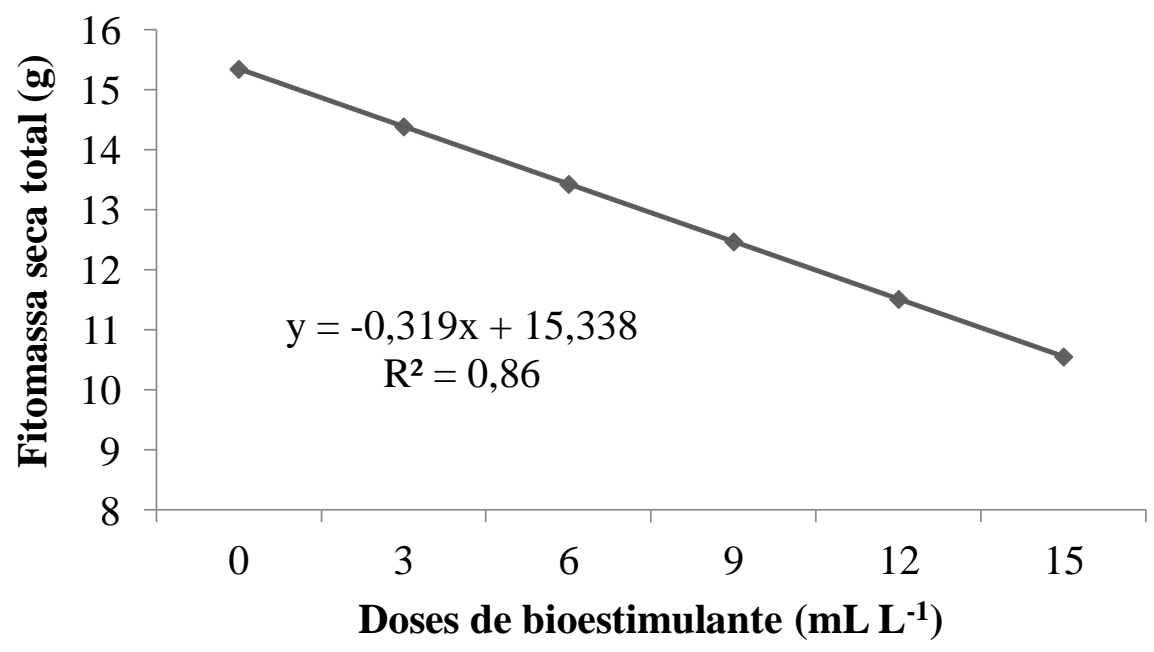

Figura 6. Fitomassa seca total $\left(\mathrm{g}_{\text {planta }}{ }^{-1}\right)$ de alface Amanda, aos 49 dias após o transplantio, em resposta à aplicação de bioestimulante nas mudas após o transplantio. Campus de Chapadão do Sul - MS.

A utilização de reguladores vegetais, segundo Silva et al. (2006), tem eficácia variável de acordo com o estado geral da planta, o comportamento do material, o momento e a forma da aplicação, tendo em vista o momento de maior sensibilidade dos tecidos, proporcionando ou não a entrada das substâncias no citoplasma.

Desta forma infere-se que o transplantio não representa o melhor momento para a aplicação de reguladores vegetais em mudas de alface da cultivar Amanda. De modo geral, todos os resultados obtidos, com exceção do número de folhas, foram desfavoráveis para o crescimento desta cultivar, prejudicando seu rendimento final.

Assim, é de fundamental importância a realização de novas pesquisas voltadas à utilização de bioestimulantes em diferentes cultivares de alface para a definição de concentrações adequadas ao crescimento, produtividade e qualidade, resultando em consequente ganho comercial para o produtor rural.

\section{CONCLUSÕES}

Na concentração de 7,0 mL L ${ }^{-1}$ de bioestimulante, aplicado em mudas de alface após o transplantio foi atingido o maior número de folhas por planta.

O bioestimulante foi prejudicial para as características diâmetro de cabeça, fitomassa fresca de folha, fitomassa seca de folhas e fitomassa seca total para a alface cultivar Amanda, quando aplicado na fase de transplantio. 


\section{REFERÊNCIAS}

ALBRECHT, L. P.; BRACCINI, A. L.; ÁVILA, M. R.; BARBOSA, M. C.; RICCI, T. T.; ALBRECHT, A. J. P. Aplicação de biorregulador na produtividade do algodoeiro e qualidade de fibra. Scientia Agraria, Curitiba-PR, v. 10, n. 3, p. 191-198, 2009.

BERNARDES SOARES, M. B. Efeito da pré-embebição de sementes de alface em solução bioestimulante. Biotemas, Florianópolis-SC, v. 25, n. 2, p. 17-23, 2012.

CAMPOS, M. F.; ONO, E. O.; BOARO, C. S. F.; RODRIGUES, J. D. Análise de crescimento em plantas de soja tratadas com substâncias reguladoras. Biotemas, Florianópolis-SC, v. 21, n. 3, p. 53-63, 2008.

CASTRO, P. R. C.; PEREIRA, M. A. Bioativadores na agricultura. In: GAZZONI, D. L. (Ed.). Tiametoxam: uma revolução na agricultura brasileira. Petrópolis-RJ: Vozes, 2008. p. 118-126.

DANTAS, A. C. V. L.; QUEIROZ, J. M. O.; VIEIRA, E. L.; ALMEIDA, V. O. Effect of gibberellic acid and the bioestimulant Stimulate ${ }^{\circledR}$ on the initial growth of thamarind. Revista Brasileira de Fruticultura, Jaboticabal-SP, v. 34, n. 1, p. 8-14, 2012.

EMBRAPA. EMPRESA BRASILEIRA DE PESQUISA AGROPECUÁRIA. Sistema brasileiro de classificação de solos. Solos. Ministério da Agricultura. Pecuária e Abastecimento. 3 ed. Rio de Janeiro, 2013. 353 p.

FILGUEIRA, F. A. R. Novo manual de Olericultura: Agrotecnologia moderna na produção e comercialização de hortaliças. Viçosa-MG: UFV, 2008, 289p.

LESZCZYNSKI, R.; BRACCINI, A. L.; ALBRECHT, L. P.; SCAPIN, C. A.; PICCININ, G. G.; DAN, L. G. M. Influence of bio-regulators on the seed germination and seedling growth of onion cultivars. Acta Scientiarum Agronomy, Maringá-PR, v. 34, n. 2, p. 187-192, 2012.

LOPES, J. L. W.; BOARO, C. S. F.; PERES, M. R.; GUIMARÃES, V. F. Crescimento de mudas de alface em diferentes substratos. Biotemas, Florianópolis-SC, v. 20, n. 4, p. 19-25, 2007.

REPKE, R. A.; VELOZO, M. R.; DOMINGUES, M. C. S.; RODRIGUES, J. D. Efeitos da aplicação de reguladores vegetais na Cultura da alface (lactuca sativa) crespa var. Verônica e Americana var. Lucy brow. Revista Nucleus. Ituverava-SP, v. 6, n. 2, p. 1-12, 2009.

RÓS, A. B.; NARITA, N.; ARAÚJO, H. S. Uso de regulador de crescimento na cultura da batata-doce. Científica, Jaboticabal-SP, v. 43, n. 2, p. 135-142, 2015.

SALA, F.C.; COSTA, C.P. 'GLORIOSA': Cultivar de alface americana tropicalizada. Horticultura Brasileira, Brasília-DF, v.26, n. 3, p.409-410, 2008.

SILVA, J.A.A.; STUCHI, E.S.; SEMPIONATO, O.R. Efeitos de doses de ácido giberélico na produção e qualidade de frutas de laranja Natal'. Laranja, Cordeirópolis-SP, v. 27, n. 1, p. 71-82, 2006.

STOLLER DO BRASIL. Stimulate Mo em hortaliças: informativo técnico. Cosmópolis-SP: Stoller do Brasil, Divisão Arbore, 1998. 1 p.

TAIZ, L.; ZEIGER, E. Fisiologia vegetal. 4.ed. Porto Alegre: Artmed, 2009. 820p.

VIEIRA, E. L.; ALMEIDA, A. Q. Efeito de estimulante vegetal no crescimento e produção de fumo Brasil-Bahia. Pesquisa Agropecuária Tropical, Goiânia-GO, v. 40, n. 4, p. 468-475, 2010. 